\title{
California Food and Fiber Futures: creating a vision for the 21 st century
}

BARBARA SCHNEEMAN

Dean, College of Agricultural and Environmental Sciences UC Davis

ROSS MacDONALD

Director of Special Projects, CA\&ES

UC Davis
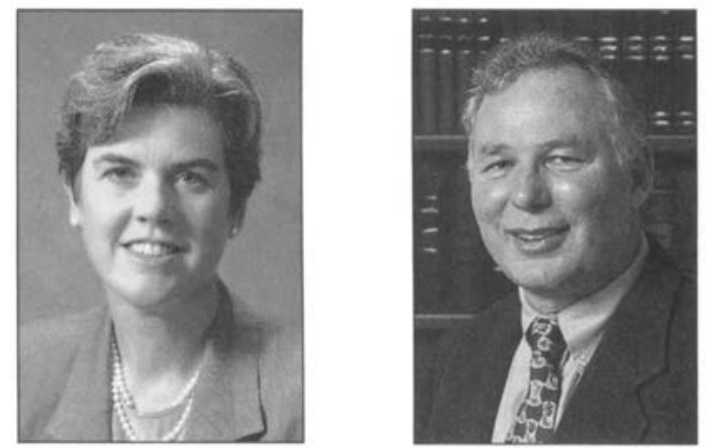

I n 1993 the W.K. Kellogg Foundation launched a national initiative to help colleges of agriculture respond to rapid social and economic change, both now and in the 21st century. The Food Systems Professions Education Initiative recognized that agricultural sciences had long ago evolved beyond "cows and crops." Today's colleges of agriculture train scientists and food systems professionals in a wide array of disciplines related to society's concerns, including environmental protection, natural resource conservation, sustainable agriculture, food safety, and farm labor conditions. While agricultural sciences have expanded, the Kellogg Foundation noted that key leaders in agriculture and higher education, and many in the general public, question the effectiveness and responsiveness of the entire food system and its higher education component.

In January 1997, the Kellogg Foundation funded the California Food and Fiber Futures Project (CF3). Led by the UC Davis campus, the project involves California's three postsecondary education systems and numerous "stakeholders." Stakeholders are those who have a share or interest in the system, such as consumers, farmworkers, inner-city populations, food bank managers, growers, processors, distributors and retailers.

The Kellogg initiative comes at a time when California agriculture is under intense pressure from increasing population. Land is no longer freely available; competition is fierce among growers, developers, environmentalists and other resource users. In addition, an increasingly urbanized population, remote from the farm, continues to expect high quality food and clothing at reasonable prices, but needs a better understanding of food, fiber and environmental systems.

California's higher education system faces a dual challenge: that of clarifying its mission - to emphasize the total agricultural and environmental system, from production through consumption (as stated by former UC Davis Chancellor James Meyer in 1993) - and that of redefining its public and scientific purpose amid rapid scientific change and public debate and discord.

Just how should higher education meet our pressing needs, as it prepares professionals to preserve the environment, maintain agricultural land, and serve a diverse constituency?

A 28-member CF3 Steering Committee has been formed to begin answering that question. Its membership includes representatives from four state colleges, five community colleges, three UC campuses, UC's Division of Agricultural and Natural Resources, and eight stakeholder groups. Among the groups represented are farmworkers, minority farmers, Bank of America, and USDA's Natural Resource Conservation Service.
The committee has established the following purposes: (1) to create a vision for the future of California agriculture, including the relevant higher education systems, through statewide discussions expected to involve hundreds of participants; (2) to make education about the food and fiber system more relevant to future students; (3) to build effective partnerships among colleges of agriculture in California and with their constituents, and (4) to promote experimentation that will create new models to address educational issues in the food and fiber system.

California colleges of agriculture must respond to increasingly diverse constituencies, with significantly different financial and personal resources, and divergent cultures. These constituencies, whether urban or rural, whether recent immigrants or longtime residents, must be brought into the educational system. We must look at instruction and how it is delivered: How does curriculum get to the many who could benefit from it, and what role will food and fiber professionals play in delivering it? For instance, new technologies are touted as the wave of the future, but too little is known about how to harness their power in reaching diverse groups.

Because funding for postsecondary education has declined as the system has become more complex, collaboration among colleges and universities is essential. Further, higher education institutions must recognize and reward faculty for the additional effort required to create new educational models and work collaboratively.

In early 1998 the CF3 project will convene meetings around the state to obtain input from stakeholders in the food and fiber system. Participants will work in small groups to formulate a shared vision of the food and fiber systems and how higher education can best prepare future professionals for those systems. They will also make specific suggestions for what California's colleges and universities could be doing now to prepare agricultural and environmental professionals for the future.

The future of the state and its varied and prodigious contributions to food and fiber knowledge, production, distribution, and consumption depends on effective collaborations across disciplines, across institutions, and across a range of stakeholders. It will require sustained leadership and skillful redirection of resources. Colleges and universities must enhance communication with the public and revitalize cooperative efforts to achieve a preferred future for higher education in the areas of agriculture and the environment.

(Readers of California Agriculture are invited to participate in statewide discussions. Contact Program Coordinator Ellen Lee at 530-754-9880 for more information.) 